\title{
AUMENTO DO RENDIMENTO METÁLICO DO LAMINADOR DE BOBINAS DE FIO MÁQUINA E VERGALHÃO*
}

\author{
Rafael Lopes ${ }^{1}$ \\ Daniel Mesquita Duarte ${ }^{2}$ \\ Rogério Ferreira Ribeiro ${ }^{3}$ \\ Elias Ferreira da Silva Junior ${ }^{4}$ \\ Leandro Luís da Silva ${ }^{5}$ \\ Isabel Cristina Silvestre Baião Tavares Pimentel ${ }^{6}$
}

\begin{abstract}
Resumo
O rendimento metálico é um dos principais indicadores de processo de laminação de longos, uma vez que tem influência direta na redução do custo de produção, sendo fundamental no atual cenário econômico da siderurgia brasileira. Em função disso faz-se necessário identificar as principais causas de perdas metálicas para aumentar o índice desse indicador, utilizando a metodologia DMAIC. Como resultado houve o aumento de $1,22 \%$ alcançado pela otimização dos parâmetros de processo do tratamento térmico, redução do comprimento do descarte da cabeça e cauda da barra na tesoura e melhoria na automação das válvulas do sistema de têmpera e autorevenido.
\end{abstract}

Palavras-chave: Rendimento metálico; Custo de produção; DMAIC; Tratamento térmico.

\section{METALLIC INCOME INCREASE IN WIRE ROD AND REBAR ROLLING PROCESS}

\begin{abstract}
The metal income is one of the long rolling process indicators, since it has direct influence on the reduction of cash cost is critical in the brazilian steel industry's current economic scenario. In function, it is necessary to identify the main causes of metal losses to increase the rate of this indicator using the DMAIC methodology. As a result there was an increase of $1.22 \%$ achieved by optimizing the heat treatment process parameters, reduction of the head and tail crop cut length in the shear and improved automation of valves quenching and self-tempering system.
\end{abstract}

Keywords: Metallic income; cash cost; DMAIC; heat treatment.

1 Engenheiro Metalurgista UFF, Engenheiro de Processo, Votorantim Siderurgia, Resende, Rio de Janeiro, Brasil.

2 Engenheiro Eletricista INATEL, Consultor de automação, Votorantim Siderurgia, Resende, Rio de Janeiro, Brasil.

3 Engenheiro Metalurgista UFF, Mestre em Engenharia de Materiais USP EEL, Facilitador de Melhoria, Votorantim Siderurgia, Resende, Rio de Janeiro, Brasil.

4 Técnico em Eletrônica ETPC, Operador de Cabine Central, Votorantim Siderurgia, Resende, Rio de Janeiro, Brasil.

5 Engenheiro Produção UNESA, Técnico Especialista, Votorantim Siderurgia, Resende, Rio de Janeiro, Brasil.

6 Técnico em Metalmecânica ETPC, Inspetora de Qualidade, Votorantim Siderurgia, Resende, Rio de Janeiro, Brasil. 


\section{INTRODUÇÃO}

No atual cenário econômico do Brasil, que sofre com a concorrência do aço importado chegando ao mercado brasileiro a baixo custo, a redução dos custos de produção é vital para a continuidade da operação das usinas siderúrgicas nacionais. Para isso, é necessário aumentar o índice de um dos principais indicadores que influenciam diretamente no cash cost do laminador de bobinas da Votorantim de Resende-RJ, o rendimento metálico.

\section{MATERIAIS E MÉTODOS}

O método utilizado neste trabalho foi o DMAIC, que consiste nas etapas de Definição, Medida, Análise, Melhoria e Controle, metodologia esta, que visa auxiliar na priorização e na otimização de recursos, com ganhos sem necessidade de grandes investimentos. Segue abaixo o gráfico (Figura 1) com o histórico do rendimento metálico do primeiro quadrimestre de 2014 na base 100.

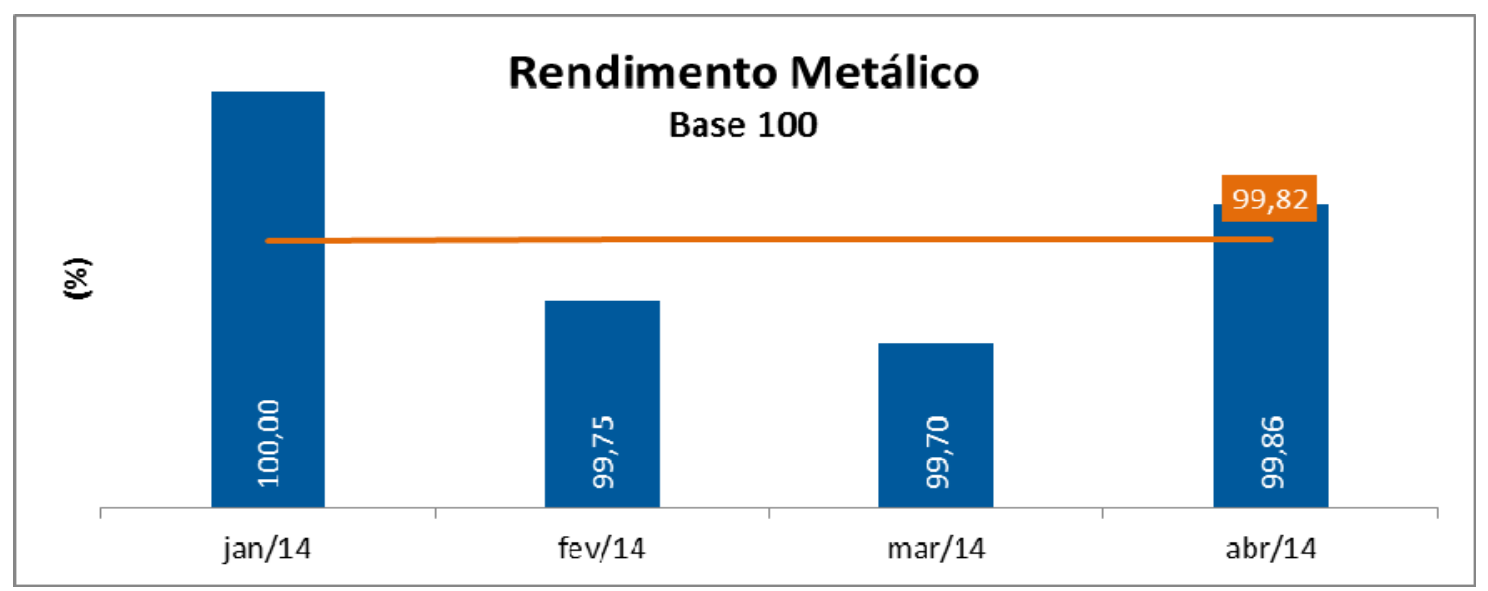

Figura 1. Rendimento Metálico do Laminador da Votorantim Siderurgia em Resende

Foram levantadas as perdas do rendimento metálico no longo do processo de laminação, onde foram observadas as maiores perdas. As figuras 2 e 3 mostram, respectivamente, as perdas metálicas do laminador na base 100 e o layout de perdas.

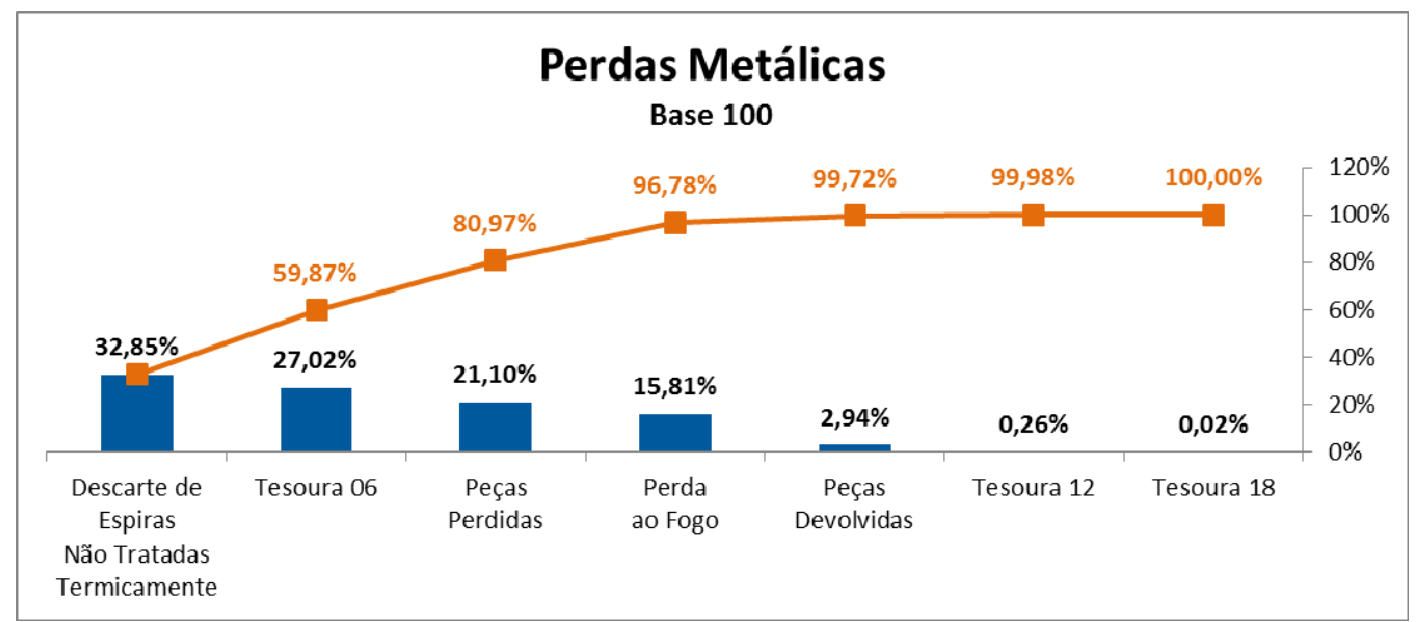

Figura 2. Perdas Metálicas do Laminador da Votorantim Siderurgia em Resende no $1^{\circ}$ Quadrimestre de 2014 


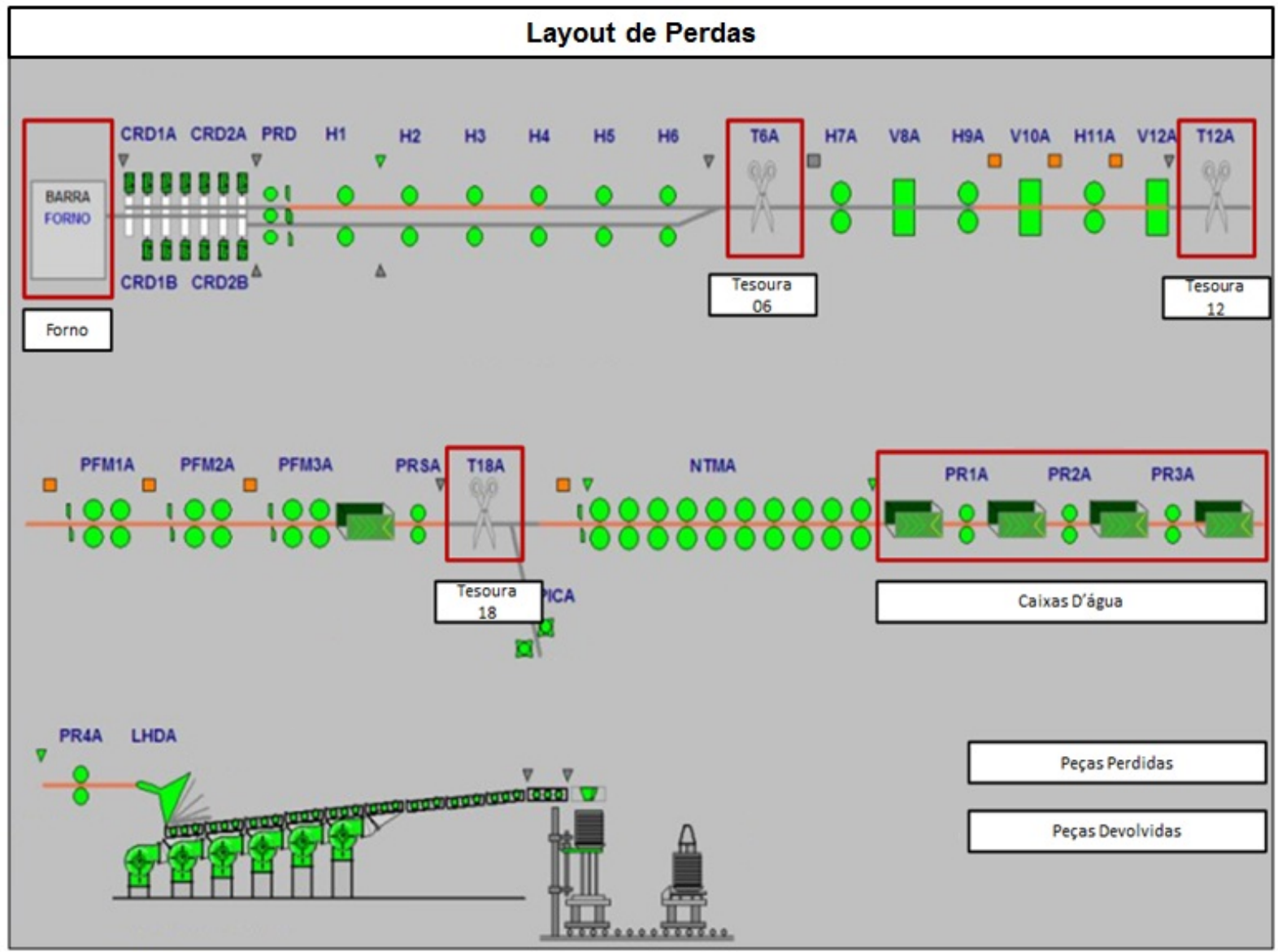

Figura 3. Layout das Perdas Metálicas no Laminador de Resende

Foi realizado um Brainstorming a fim de levantar todos os X's que impactam no rendimento metálico, conforme Figura 4.

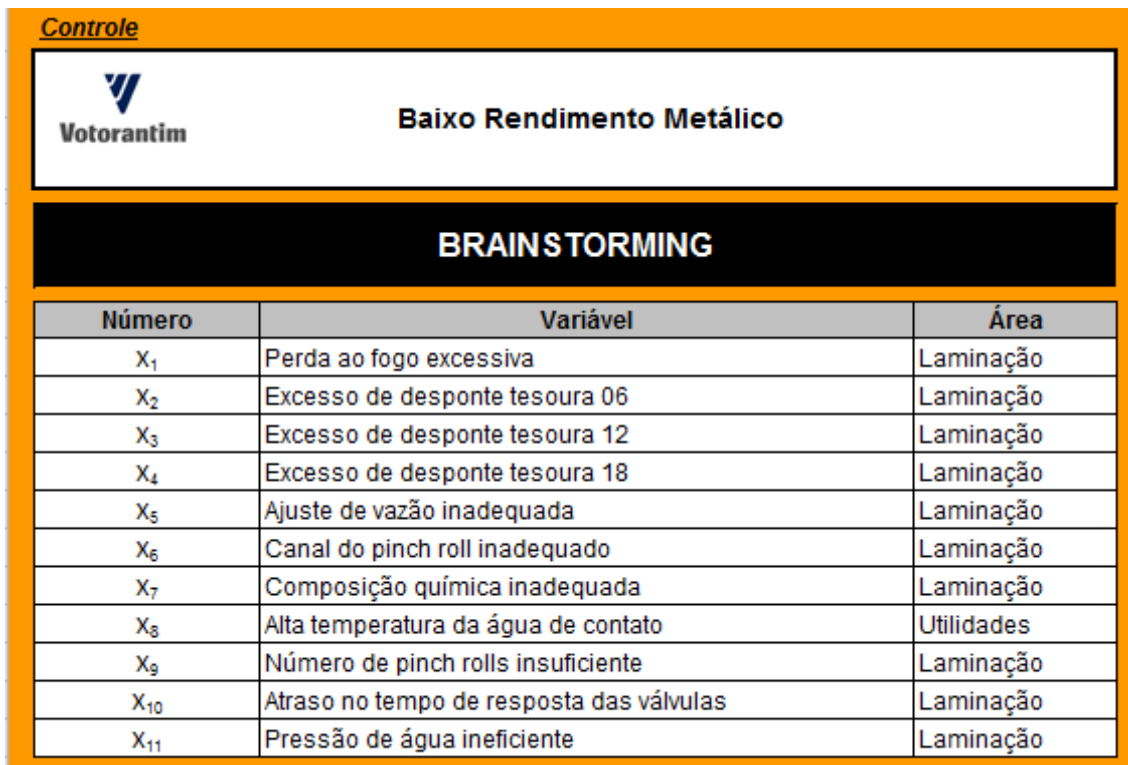

Figura 4. Brainstorming das Perdas Metálicas no Laminador de Resende

Após conhecer os X's do projeto, foi elaborada a Matriz Causa \& Efeito, que tem como objetivo de estimar o efeito/consequência de cada $X$ levantado no $Y$ do projeto, que neste caso é o rendimento metálico. A matriz é vista na figura 5. 


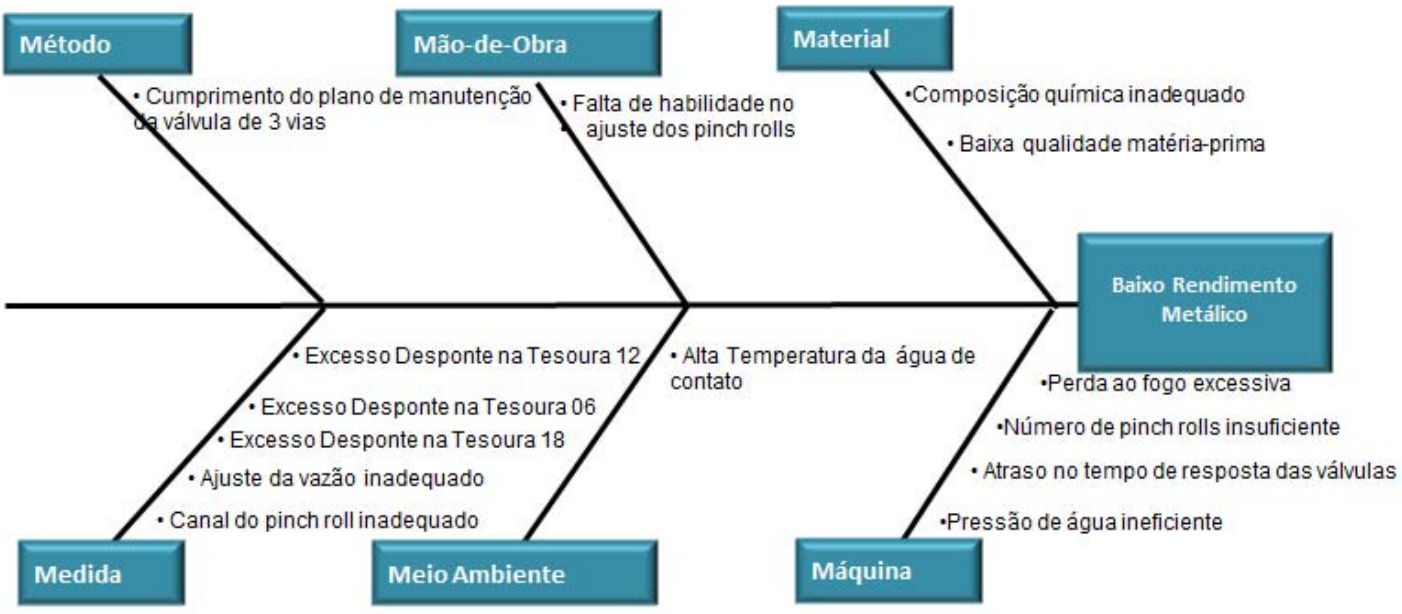

Figura 5. Diagrama de Causa e Efeito

Com esta informação, é possível criar a Matriz Esforço x Impacto, que é importante para priorizar as ações do trabalho. Ela pode ser vista na figura 6.

\section{Matriz Esforço X Impacto}

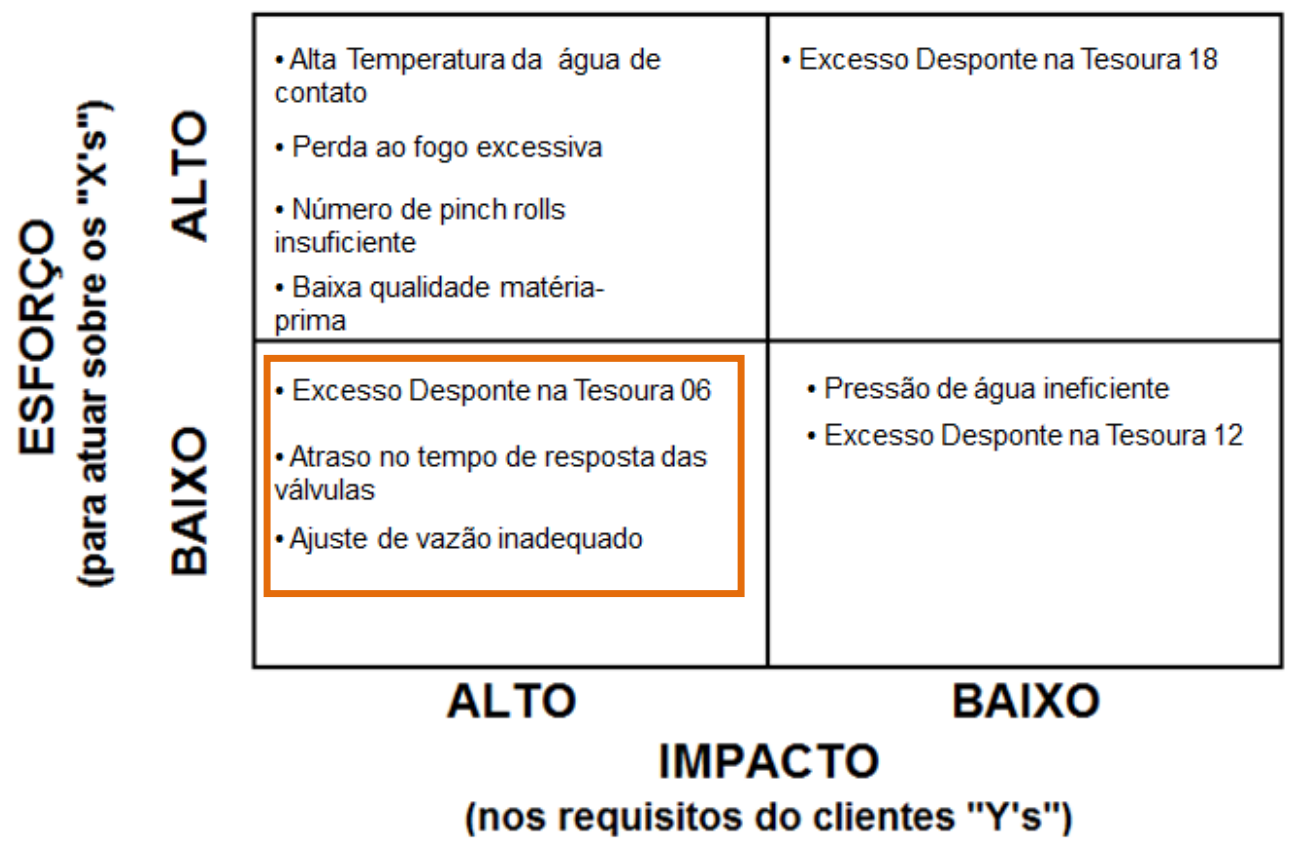

Figura 6. Matriz de Esforço Impacto 


\subsection{PROCESSO DE TRATAMENTO TÉRMICO}

Para se prever a microestrutura formada, para uma dada condição de resfriamento, pode-se utilizar os diagramas TTT (Temperatura Tempo Transformação) e CCT (Continuous Cooling Transformation) ${ }^{(3)}$. No primeiro caso, o material é resfriado a uma dada temperatura e a transformação ocorre isotermicamente. Já nos diagramas CCT, ocorre o resfriamento contínuo do material sendo, portanto, mais aplicável em processos industriais. A constituição destes diagramas é dependente, principalmente da composição química e do tamanho de grão do material, dentre outros fatores ${ }^{(1)}$. Exemplos destes diagramas encontram-se na figura 7 a seguir:

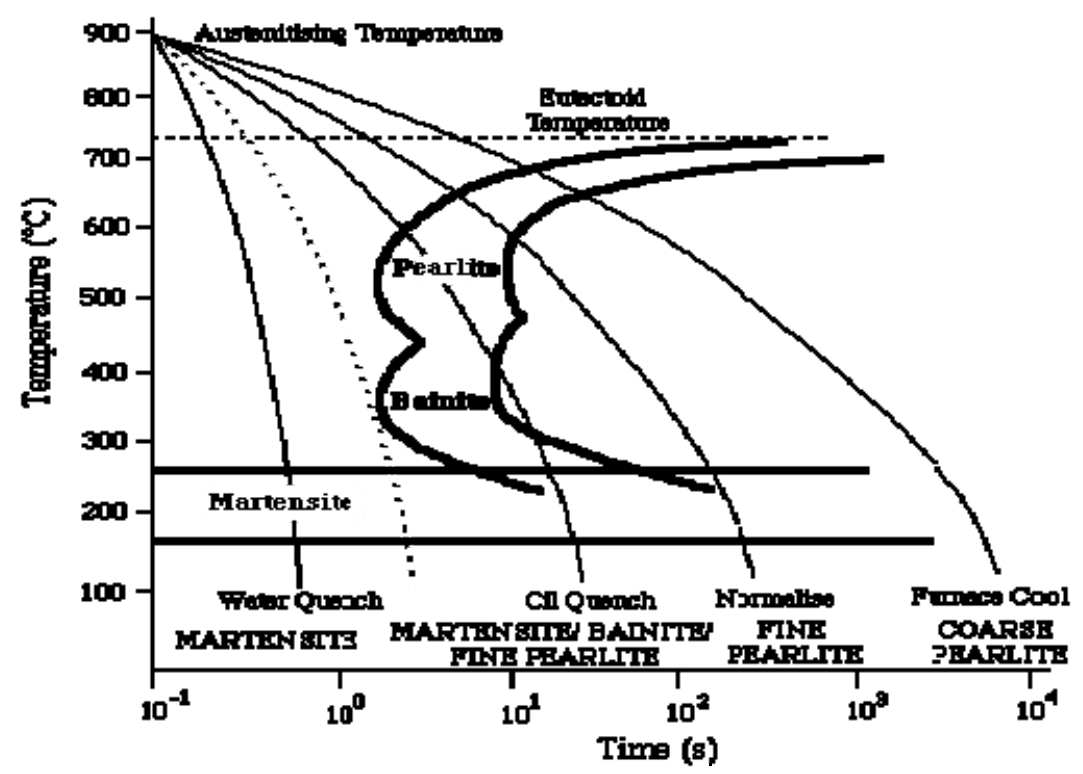

Figura 7 - Diagrama CCT para um aço eutetóide. (1)

Nos aços, a martensita é obtida através do resfriamento brusco a partir da fase austenítica, sem difusão e por um cisalhamento da estrutura e expansão da rede da austenita, onde os grãos de martensita nucleiam e crescem rapidamente. Isso é conhecido como Têmpera. A martensita forma agulhas (Figura 8) em aços alto carbono e de ripas para baixo carbono.

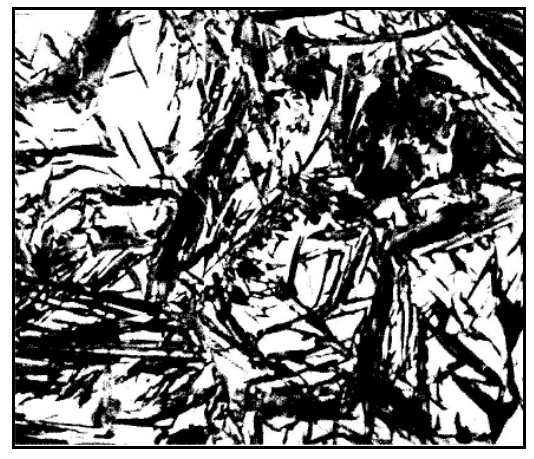

Figura 8 - Micrografia de martensita (agulhas) e austenita não-transformada (regiões claras) após resfriamento rápido (têmpera). ${ }^{(2)}$

Outro tipo de tratamento térmico é o revenimento da martensita, por meio do aquecimento, aliviando as tensões e difusão do carbono para fora da rede 
tetragonal, resultando na precipitação de carbetos, diminuindo a dureza e melhorando a ductilidade. (4)

No laminador da Votorantim Siderurgia é realizado o tratamento térmico de tempera e revenido, como será visto a seguir.

\subsection{PROCESSO DE TRATAMENTO TÉRMICO DO LAMINADOR MORGAN}

Neste processo é possível obter uma alta taxa de resfriamento (aproximadamente $200{ }^{\circ} \mathrm{C} / \mathrm{s}$ ) da região externa da barra através de um sistema de resfriamento com água logo após o último passe de laminação. Nesta etapa a barra encontra-se com a temperatura em torno de $1000{ }^{\circ} \mathrm{C}$ e através do resfriamento brusco, tem-se a transformação da austenita em martensita na região externa, enquanto que o núcleo permanece com austenita. A camada martensítica é revenida pela dissipação do calor oriundo do núcleo devido ao gradiente térmico de temperatura. A figura 9 ilustra curva do tratamento térmico de tempera e auto revenido utilizado na Votorantim Siderurgia. (5)

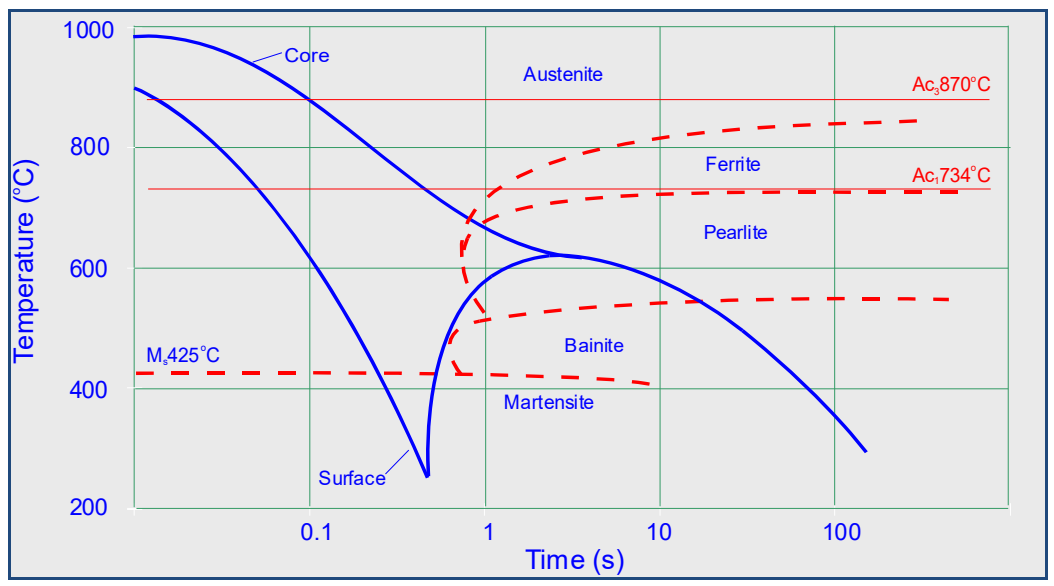

Figura 9 - Curva Tratamento Térmico de Tempera e Auto revenido Votorantim Siderurgia. ${ }^{(5)}$

A seção transversal de uma barra de aço (figura 10) após este tratamento térmico contém um núcleo envolvido com uma camada espessa predominante de martensita da superfície até a zona de transição. A austenita no centro da barra irá resfriar até a região próxima ao nariz da temperatura de início da transformação perlítica, onde o resfriamento lento do núcleo até a temperatura ambiente, transformando a austenita em perlita e ferrita com uma granulação. Todo o tratamento térmico utilizado no Laminador da Votorantim é controlado pelo sistema METCS@ .

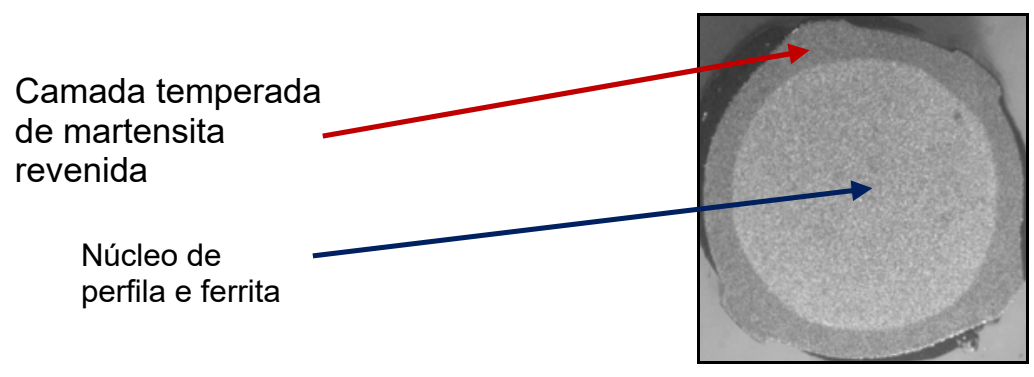

Figura 10 - Seção transversal de uma barra tratada termicamente através do controle do sistema METCS@. (5) 


\section{RESULTADOS E DISCUSSÃO}

As principais perdas metálicas que foram consideradas neste trabalho foram o descarte de espiras não tratadas termicamente e o desponte da tesoura 06.

\subsection{Tratamento Térmico}

No tratamento térmico foi observado que os parâmetros utilizados na têmpera e auto revenido não eram suficientes para uma profundidade da camada martensítica adequada nas primeiras espiras. A curva 1 representa a curva real enquanto a curva 02 indica a curva necessária ao tratamento das primeiras espiras (Figura 11).

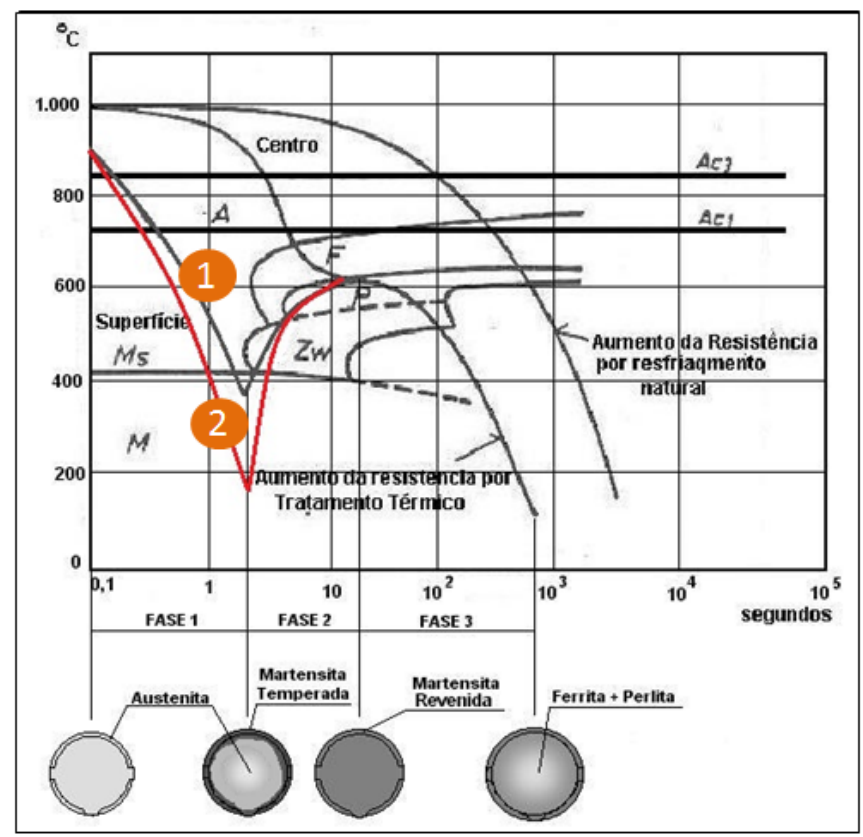

Figura 11. Comparação entre as curvas de resfriamento real (01) e a ideal para tratar termicamente os vergalhões no laminador da Votorantim Siderurgia em Resende

Desta forma, a profundidade de têmpera obtida nas primeiras espiras não era suficiente para atender o limite de escoamento mínimo requisitado na norma NBR 7480 , como pode ser visto na figura 12A. Foram alterados os parâmetros de tratamento térmico do vergalhão aumentando a profundidade da têmpera $\mathrm{e}$ reduzindo o descarte de espiras. A microestrutura obtida apresentou uma camada de martensita revenida mais espessa, conforme figura 12B.
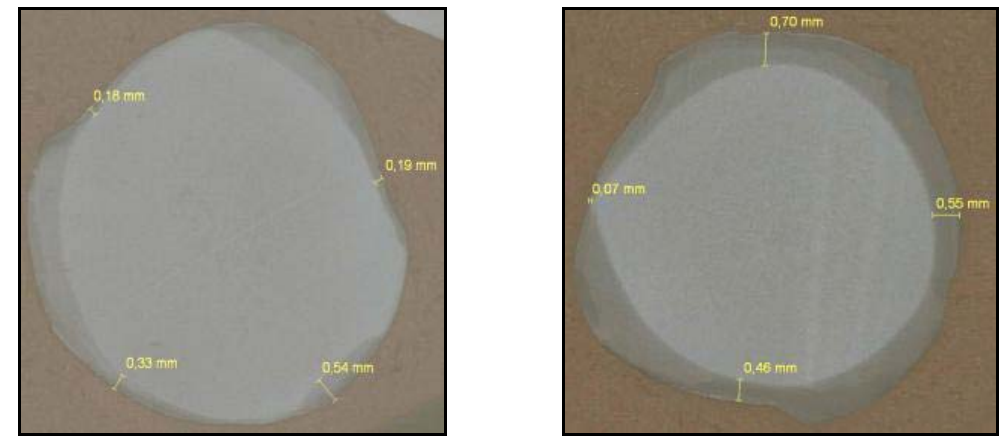

Figura 12A e 12B. Comparação entre as camadas de martensita antes e após a alteração dos parâmetros de processo 
Após alteração nos parâmetros de processo foi possível obter uma redução significativa no descarte das primeiras espiras de $55 \%$ em função do aumento do limite de escoamento (ver gráfico do CA50 6,3 mm).

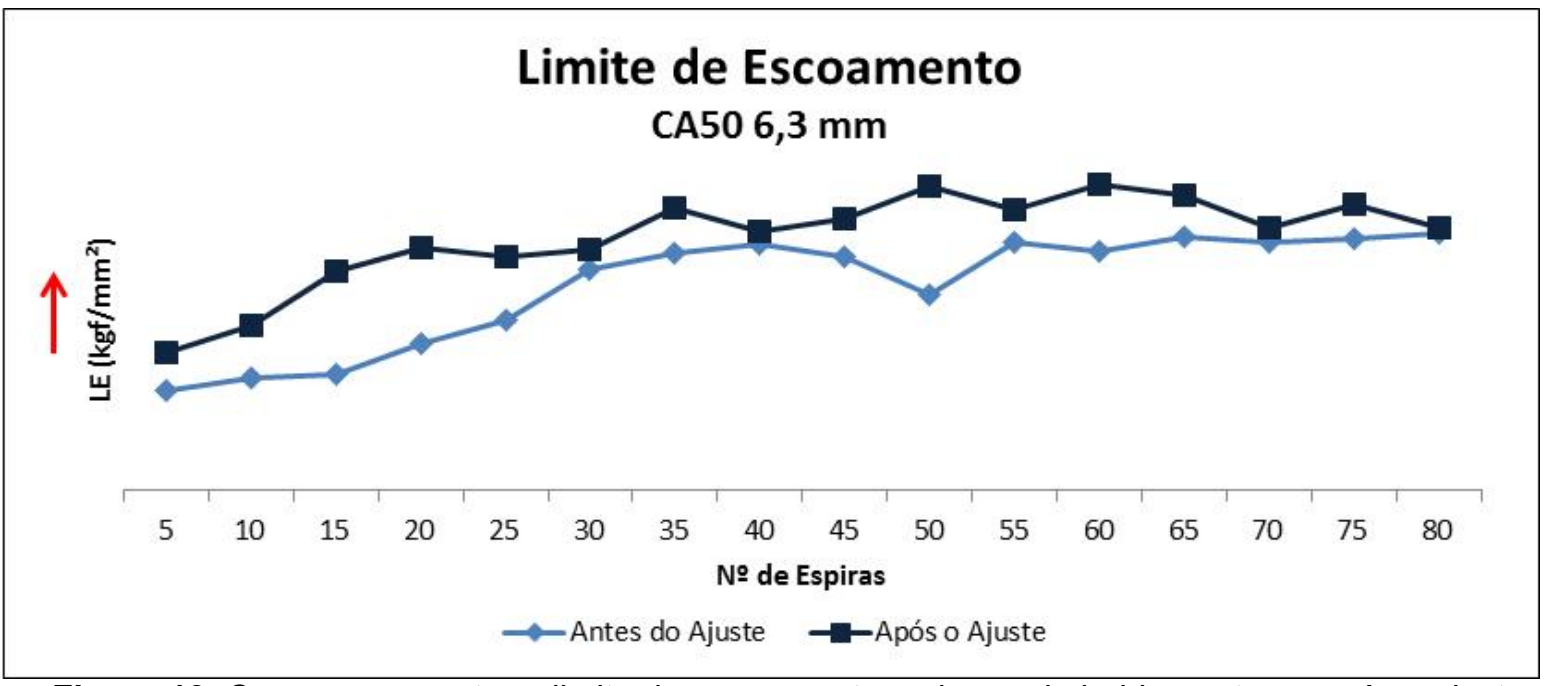

Figura 13. Comparação entre o limite de escoamento ao longo da bobina antes e após o ajuste

\subsection{Desponte da Tesoura 06}

A tesoura 06, localizada após a última gaiola do Desbaste, tem a função de descartar a cabeça e cauda da barra devido baixa temperatura e defeitos de tarugo em função de trincas internas e corte irregular. Porém, havia um descarte excessivo das pontas da barra por falta de caracterização do comprimento do desponte isento de defeito.

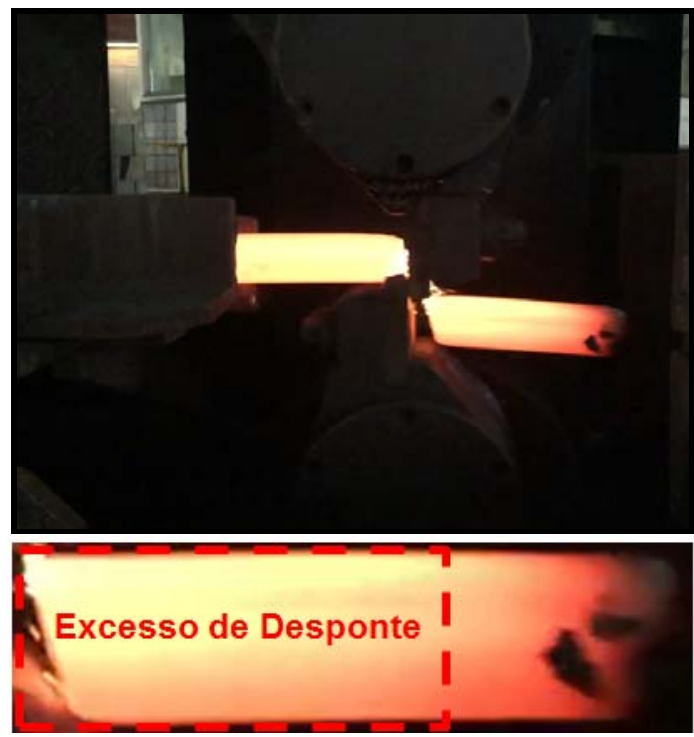

Figura 14. Desponte da Tesoura 06

Em função disso, foram realizadas análises da extensão da trinca nas extremidades da barra onde observou-se a oportunidade de reduzir o comprimento do desponte da cabeça e cauda da barra conforme mostrado nas figuras 15, 16 e 17 a seguir: 


\begin{tabular}{|c|c|c|c|c|c|c|}
\hline \multicolumn{7}{|c|}{ Desponte da Tesoura 06 } \\
\hline $\begin{array}{c}\text { Ajuste } \\
\text { Comprimento } \\
\text { Cabeça }(\mathrm{mm})\end{array}$ & $\begin{array}{c}\text { Comprimento } \\
\text { Cabeça Real } \\
(\mathrm{mm})\end{array}$ & $\begin{array}{c}\text { Ajuste } \\
\text { Comprimento } \\
\text { Cauda }(\mathrm{mm})\end{array}$ & $\begin{array}{c}\text { Comprimento } \\
\text { Cauda Real }(\mathrm{mm})\end{array}$ & $\begin{array}{c}\text { Peso } \\
\text { Cabeça } \\
(\mathbf{k g})\end{array}$ & $\begin{array}{c}\text { Peso } \\
\text { Cauda } \\
(\mathrm{kg})\end{array}$ \\
\hline Antes & $\mathbf{3 5 0}$ & $\mathbf{2 9 0}$ & $\mathbf{2 0 0}$ & $\mathbf{2 2 0}$ & $\mathbf{9 , 7 0 5}$ & $\mathbf{7 , 4 5 0}$ \\
\hline Depois & $\mathbf{2 5 0}$ & $\mathbf{2 0 0}$ & 100 & 125 & $\mathbf{6 , 3 4 5}$ & $\mathbf{4 , 1 0 5}$ \\
\hline Redução & $\mathbf{1 0 0}$ & $\mathbf{9 0}$ & $\mathbf{1 0 0}$ & $\mathbf{9 5}$ & $\mathbf{3 , 3 6 0}$ & $\mathbf{3 , 3 4 5}$ \\
\hline
\end{tabular}

Figura 15. Tabela com os valores de comprimento do desponte antes e após a alteração

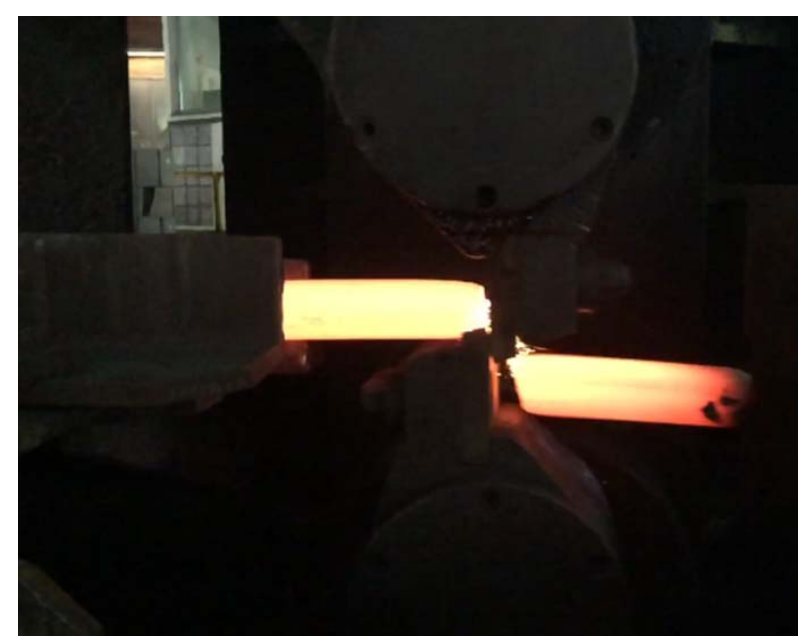

Figura 16. Corte da cabeça da barra antes do ajuste

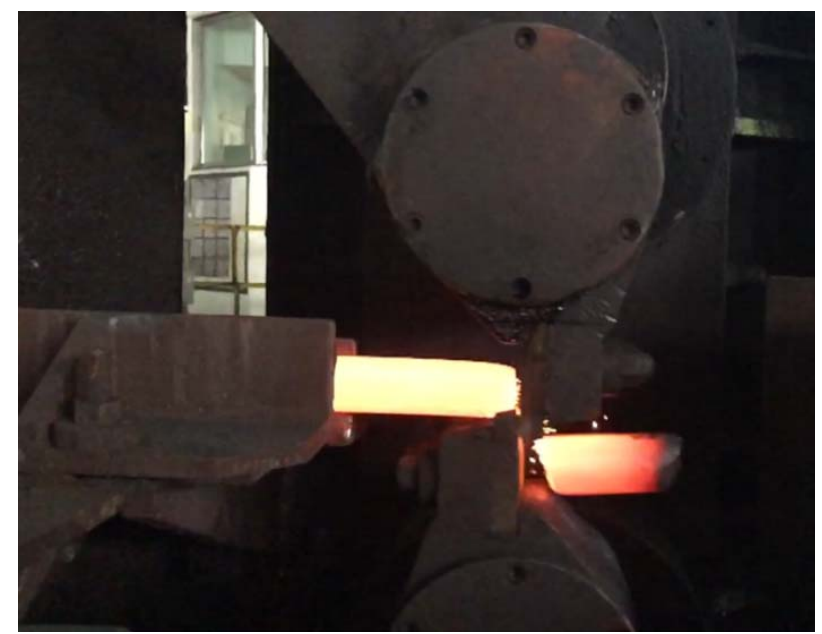

Figura 17. Corte da cabeça da barra após o ajuste

Como resultado da redução do desponte da tesoura 06, houve um aumento de $0,38 \%$ no rendimento metálico.

\subsection{Ajuste de Espiras Quentes}

O ajuste de espiras quentes depende de fatores que tem relação com a estabilidade da barra durante a abertura das válvulas da água necessária ao tratamento térmico. Estes fatores são: vazão de água, ajuste dos impulsionadores e tempo de resposta das válvulas de 3 vias. Foi observado que havia uma grande diferença no tempo de resposta das válvulas de 3 vias de uma mesma caixa d'água.

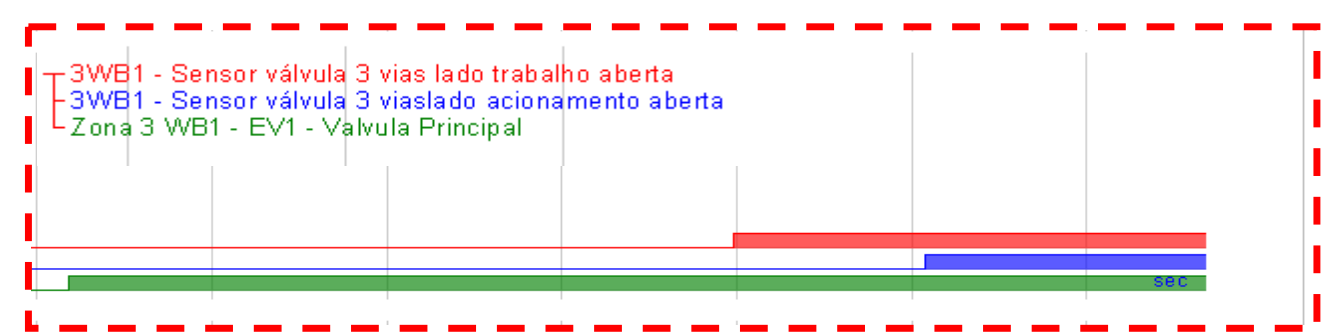

Figura 18. Comparação da abertura das válvulas de 03 vias do sistema de tratamento térmico do laminador da Votorantim Siderurgia de Resende

Em função disso, foi feita a instalação de sensores indutivos para medir o tempo de abertura das válvulas, possibilitando a criação de uma lógica onde é medido o tempo de reação das válvulas e é feita a média dos últimos 05 valores, conforme mostrado no Diagrama de Blocos (figura 19). Como resultado houve a redução na diferença do tempo de comutação entre as válvulas de 3 Vias e maior precisão de atuação. 


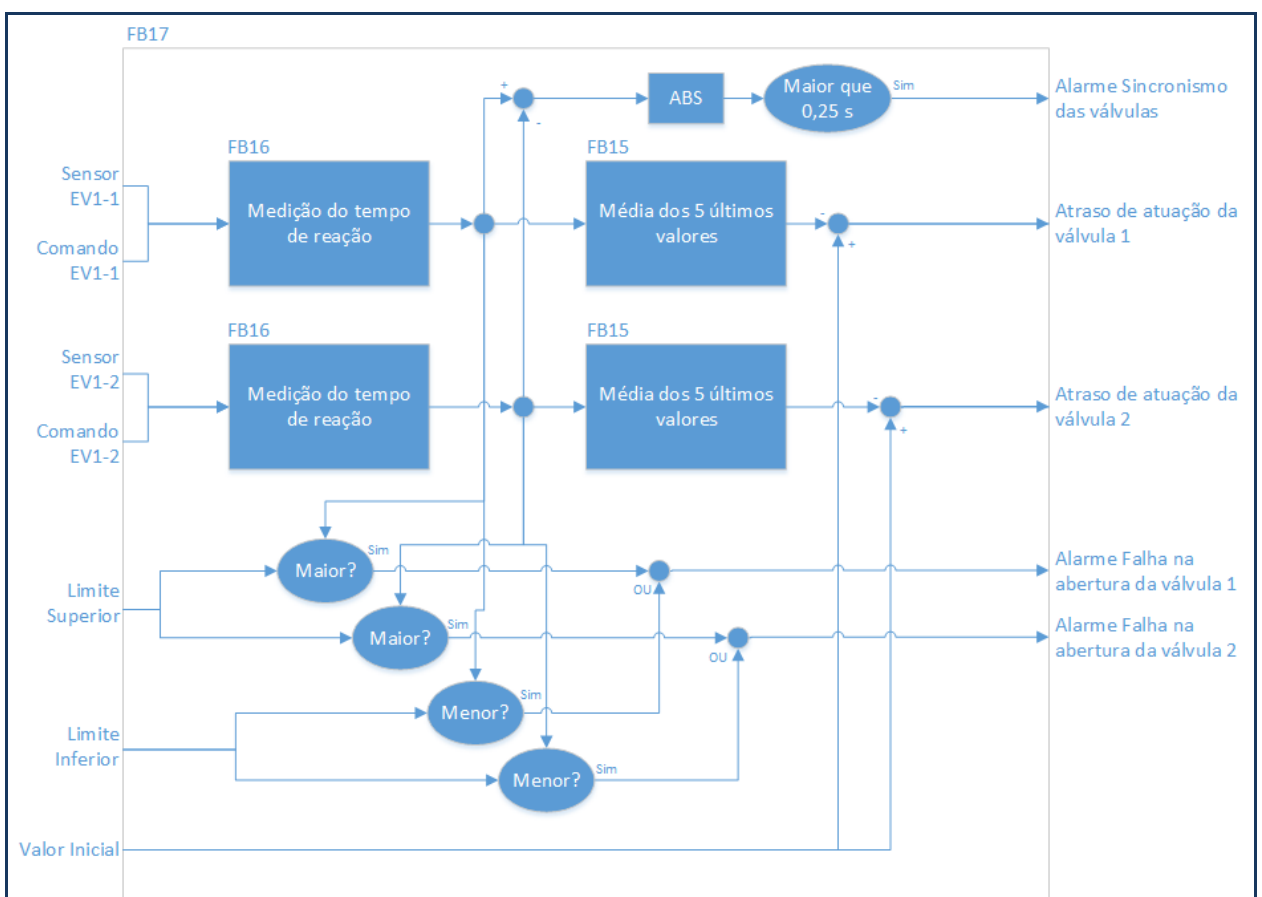

Figura 19. Diagrama de blocos da lógica aplicada à abertura das válvulas de 03 vias do sistema de tratamento térmico do laminador da Votorantim Siderurgia de Resende

A figura 20 a seguir mostra que não há diferença no tempo de abertura entre as válvulas de 03 vias das caixas d'água do tratamento térmico da laminação de Resende da Votorantim Siderurgia gerando a redução do ajuste de espiras quentes.

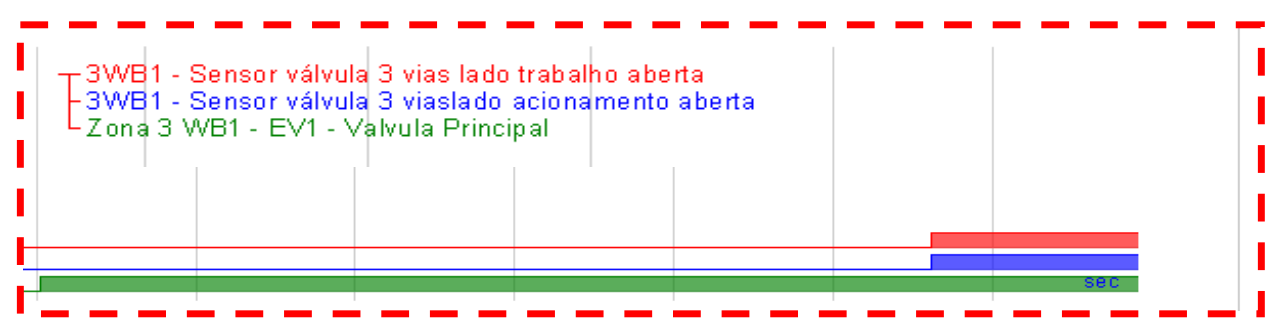

Figura 20. Comparação da abertura das válvulas de 03 vias do sistema de tratamento térmico do laminador da Votorantim Siderurgia de Resende após implantação da lógica.

A figura 21 mostra o resultado obtido para o CA50 8,0 mm onde o descarte de espiras quentes foi reduzido em $72 \%$.

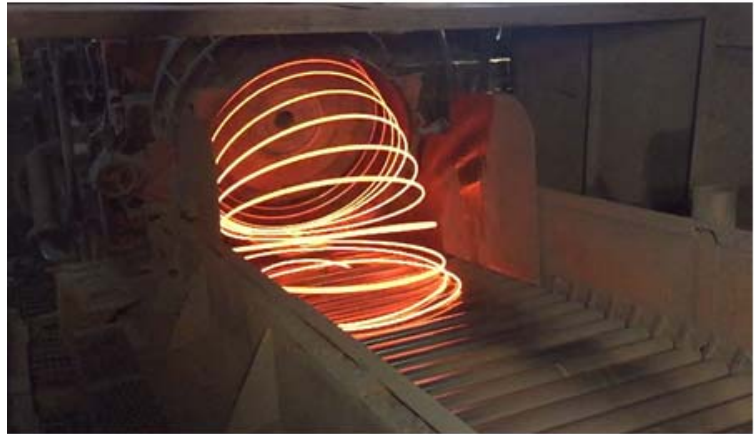

CA50 8,0 mm - Antes

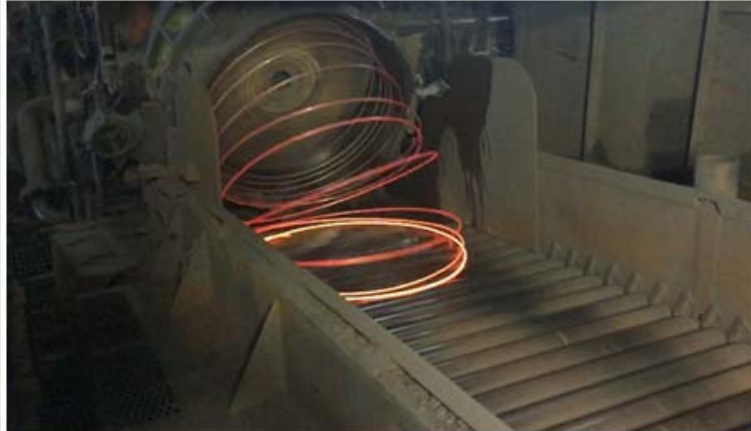

CA50 8,0 mm - Depois

Figura 21. Comparação da quantidade de espiras não tratatadas termicamente antes e após o ajuste no sistema de tratamento térmico do laminador da Votorantim Siderurgia de Resende 
Com a revisão do ajuste de espiras quentes em todas as bitolas de vergalhão produzidas em Resende obteve-se um ganho de $0,30 \%$ no rendimento metálico.

Com relação a todo o projeto, obteve-se um ganho considerável de $1,22 \%$ no rendimento metálico do laminador de Resende. A figura 22 exemplifica o ganho do rendimento metálico na base 100.

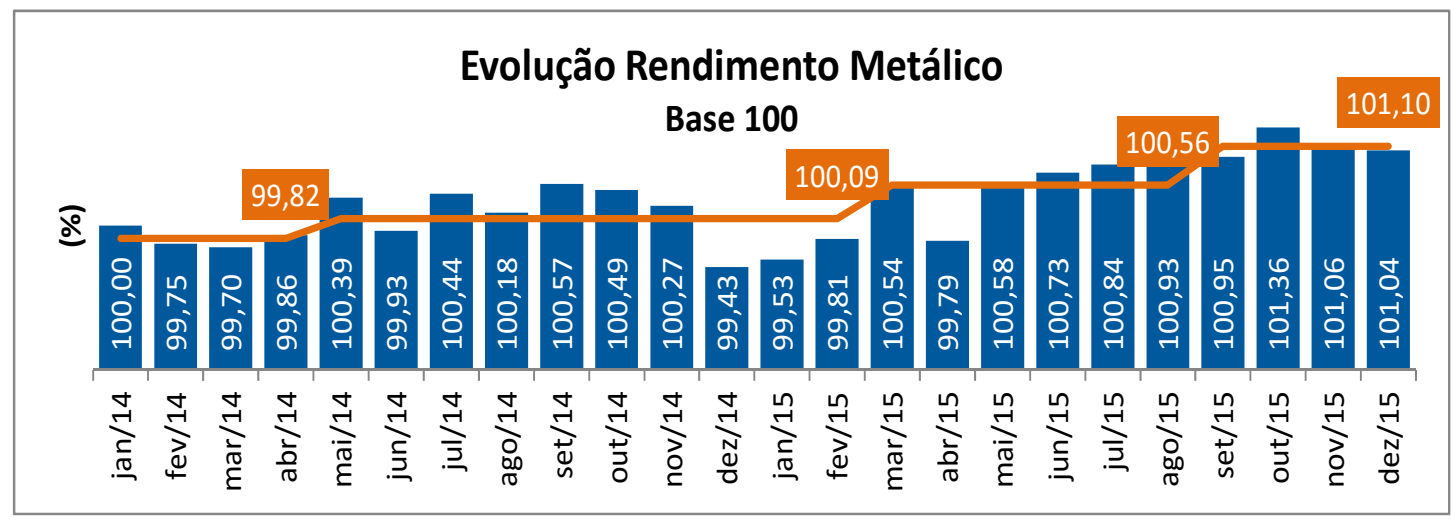

Figura 22. Evolução na Base 100 do Rendimento Metálico do laminador de Resende entre janeiro de 2014 e dezembro de 2015.

\section{CONCLUSÃo}

A utilização do DMAIC para aumentar o rendimento metálico se mostrou eficaz, pois proporcionou considerável redução de custo com baixo investimento levando as seguintes conclusões:

- A otimização dos parâmetros do tratamento térmico possibilitou alcançar mais rapidamente as propriedades mecânicas especificadas reduzindo o descarte de espiras;

- A redução do desponte da tesoura 06 elevou o rendimento metálico mantendo a principal função de retirar os defeitos de tarugos nas extremidades das barras;

- A redução do descarte de espiras quentes pelo ajuste no controle de abertura das válvulas de 03 vias, com maior confiabilidade e precisão do sistema, redução do cash cost do laminador e aumento da satisfação dos empregados pelo menor peso descartado de espiras.

\section{REFERÊNCIAS}

1 UNIVERSITY OF CAMBRIDGE. Department of Materials Science \& Metallurgy.

Disponível em: <http://www.msm.cam.ac.uk/phasetrans/2000/practicals/AP3/AP3.html>;

2 A. F. Padilha e P. R. Rios, Transformação de Fases. Editora Artliber, São Paulo, 2007;

3 W. D. Callister Jr., Ciência e Engenharia de Materiais: uma abordagem integrada. LTC Editora, Rio de Janeiro, 2006;

4 A. L. V. Costa e Silva e P. R. Mei, Aços e Ligas Especiais. Editora Edgard Blücher, São Paulo, 2006;

5 Copyright (C) Morgan Construction Company Manual Morgan Votorantim; Water Boxes Processing; Resende, 2009. 